\title{
The moderate predictive value of serial serum CRP and PCT levels for the prognosis of hospitalized community-acquired pneumonia
}

\author{
Shuren Guo ${ }^{1,2}$, Xiaohuan Mao ${ }^{3}$ and Ming Liang ${ }^{1,2^{*}}$
}

\begin{abstract}
Background: To predict the prognosis by observing the dynamic change of C-reactive protein (CRP) and procalcitonin (PCT) for hospitalized community-acquired pneumonia (CAP).

Methods: The data were collected from January to December 2017 from the first affiliated Hospital of Zhengzhou University. Demographic and clinical patient information including age, length of hospital stay and Charlson Comorbidity Index (CCI) were recorded. Blood samples were taken for CRP, PCT, and white blood cell count (WBC). Receiver Operating Characteristic (ROC) curve was used to verify each biomarker's association with the prognosis of pneumonia.

Results: A total of 350 patients were enrolled in the study. The 30-day mortality was 10.86\%. Serial serum CRP3, CRP5, PCT3, PCT5 and PCT5C levels were statistically lower in CAP survivors than non-survivors. CRP3C $<0, C R P 5 C<0$ and $P C T 5 c<0$ were observed with a statistically lower frequency in patients with 30-day mortality and initial treatment failure. The AUC for 30-day mortality for serial CRP levels combined with CRP clearances was 0.85 (95\% Cl 0.77-0.92), as compared to an AUC of 0.81 (95\% Cl 0.73-0.9) for serial PCT levels combined with PCT clearances.

Conclusions: Serum serial CRP and PCT levels had moderate predictive value for hospitalized CAP prognosis. The dynamic CRP and PCT changes may potentially be used in the future to predict hospitalized CAP prognosis.
\end{abstract}

Keywords: Serial serum CRP, PCT, Predictive value, CAP prognosis

\section{Background}

Diagnosis of pneumonia in critically ill patients is usually challenging. Signs and symptoms with enormous heterogeneity, such as dyspnea, may be non-diagnostic or atypical, chest X-ray results may be uncertain, also complications may be confounding factors [1-3]. Thus, biomarkers of inflammation or infection, such as procalcitonin (PCT) and $\mathrm{C}$-reactive protein (CRP), have been proposed as a guide in the diagnostic process [4-6]. Elevated serum PCT and CRP were associated with community-acquired pneumonia and ventilator-associated pneumonia (VAP) $[5,7]$.

\footnotetext{
* Correspondence: mingliang@zzu.edu.cn

'Department of Clinical Laboratory, The First Affiliated Hospital of Zhengzhou University, East Jianshe Road \#1, Zhengzhou, Henan 450002, People's Republic of China

${ }^{2}$ Key Clinical Laboratory of Henan province, Zhengzhou, Henan, People's Republic of China

Full list of author information is available at the end of the article
}

CRP is a well-established biomarker in many clinical settings, but has been traditionally considered insufficient as a useful marker in the diagnosis of pneumonia. In fact, all infections, stress reactions, autoimmunity and tumor disease can contribute to the increase in serum CRP values [8].

PCT is a 116-amino acid long precursor of calcitonin, which is produced by the thyroid. In sepsis, macrophages and the monocytic cells of the liver are involved in the synthesis of PCT,which is elevated in sepsis $[9,10]$. The degree of induction of PCT correlates with the severity of systemic infection and the presence of organ dysfunction.

Due to multiple confounding factors, several studies have reported controversial results on the role of CRP and PCT in the diagnosis of pneumonia in multiple elderly patients $[1,11,12]$. The importance of serum CRP and PCT

(c) The Author(s). 2018 Open Access This article is distributed under the terms of the Creative Commons Attribution 4.0 International License (http://creativecommons.org/licenses/by/4.0/), which permits unrestricted use, distribution, and 
Table 1 Characteristics of survivors and non-survivors

\begin{tabular}{|c|c|c|c|c|}
\hline & $\begin{array}{l}\text { All patients (\%) } \\
n=350\end{array}$ & $\begin{array}{l}\text { Survivors (\%) } \\
n=312\end{array}$ & $\begin{array}{l}\text { Non-Survivors (\%) } \\
n=38\end{array}$ & $P$ value \\
\hline Age(years) & $58.53 \pm 19.1$ & $58.59 \pm 19.2$ & $58.03 \pm 18.9$ & 0.86 \\
\hline Males & $204(58.3)$ & $181(58.0)$ & $23(60.5)$ & 0.7 \\
\hline \multicolumn{5}{|l|}{ Comorbidity } \\
\hline Diabetes Mellitus & $30(8.57)$ & $27(8.6)$ & $3(7.8)$ & 0.87 \\
\hline Chronic heart disease & $100(28.57)$ & $91(29.1)$ & $9(23.6)$ & 0.48 \\
\hline Chronic liver disease & $22(6.29)$ & $20(6.4)$ & $2(5.2)$ & 0.78 \\
\hline Chronic renal disease & $47(13.43)$ & $40(12.8)$ & $7(18.4)$ & 0.34 \\
\hline Malignant disease & $26(7.43)$ & $24(7.6)$ & $2(5.2)$ & 0.59 \\
\hline History of Shock & $17(4.86)$ & $15(4.8)$ & $2(5.2)$ & 0.9 \\
\hline COPD & $22(6.29)$ & $18(5.7)$ & $4(10.5)$ & 0.25 \\
\hline Cerebrovascular disease & $39(11.14)$ & $35(11.2)$ & $4(10.5)$ & 0.9 \\
\hline Antimicrobial treatment before admission & $79(22.6)$ & $70(22.4)$ & $9(23.7)$ & 1 \\
\hline \multicolumn{5}{|l|}{ Signs and symptoms } \\
\hline Cough & 268(76.6) & $260(83.3)$ & 28(73.6) & 0.14 \\
\hline Chest pain & 116(33.1) & 106(33.9) & $10(26.3)$ & 0.34 \\
\hline Expectoration & $168(48)$ & $148(47.4)$ & $20(52.6)$ & 0.54 \\
\hline Dyspnea & 249(71.1) & $221(70.8)$ & 28(73.6) & 0.72 \\
\hline Chills & 124(35.4) & 109(34.9) & 15(39.4) & 0.58 \\
\hline Headaches & $75(21.4)$ & $58(18.5)$ & $17(44.7)$ & $<0.001$ \\
\hline Myalgia & $79(22.6)$ & $71(22.7)$ & $8(21)$ & 0.8 \\
\hline Crackles & 114(32.6) & 102(32.6) & $12(31.5)$ & 0.89 \\
\hline Fever & $110(31.4)$ & $96(30.7)$ & 14(36.8) & 0.45 \\
\hline Confusion & $5(1.4)$ & $1(0.3)$ & $4(10.5)$ & $<0.001$ \\
\hline \multicolumn{5}{|l|}{$\mathrm{CCl}$ class } \\
\hline $0-2$ & 129(36.8) & $116(37.1)$ & $13(34.2)$ & \multirow[t]{3}{*}{0.7} \\
\hline $3-5$ & 180(51.4) & 161(51.6) & $19(50)$ & \\
\hline$>5$ & $41(11.7)$ & $35(11.2)$ & $6(15.7)$ & \\
\hline CRP1 (mg/L) & $65.3 \pm 84.7$ & $66.3 \pm 85.2$ & $57.1 \pm 81.3$ & 0.53 \\
\hline CRP3 (mg/L) & $56.4 \pm 77.4$ & $50 \pm 66.4$ & $109.1 \pm 128.4$ & $<0.001$ \\
\hline CRP3C & $556.6 \pm 5056.3$ & $575.2 \pm 5334.2$ & $401.2 \pm 1242.4$ & 0.843 \\
\hline$C R P 3 C<0$ & $223(63.7)$ & $214(68.5)$ & $9(23.6)$ & $<0.001$ \\
\hline CRP5(mg/L) & $44.8 \pm 68.5$ & $37.9 \pm 61$ & $102.1 \pm 96.9$ & $<0.001$ \\
\hline CRP5C & $429.2 \pm 3489.6$ & $429.2 \pm 3670.1$ & $429.3 \pm 1207.6$ & 0.999 \\
\hline $\mathrm{CRP} 5 \mathrm{C}<0$ & $222(63.4)$ & $213(68.2)$ & $9(23.6)$ & $<0.001$ \\
\hline PCT1 (ng/mL) & $1.8 \pm 7.1$ & $1.8 \pm 7.3$ & $1.9 \pm 5.5$ & 0.96 \\
\hline РCT3 (ng/mL) & $1.7 \pm 6.3$ & $1.4 \pm 4.4$ & $4.1 \pm 14.5$ & 0.012 \\
\hline РСТ3С & $791.2 \pm 2653.8$ & $793.3 \pm 2672.6$ & $774.1 \pm 2528.7$ & 0.966 \\
\hline $\mathrm{PCT} 3 \mathrm{C}<0$ & 174(49.7) & $157(50.3)$ & $17(44.7)$ & 0.52 \\
\hline PCT5 (ng/mL) & $1.2 \pm 3.7$ & $0.8 \pm 2$ & $4.3 \pm 9.3$ & $<0.001$ \\
\hline PCT5C & $695.3 \pm 2463$ & $589.9 \pm 2298.2$ & $1555 \pm 3454.4$ & 0.022 \\
\hline PCT5c $<0$ & 179(51.1) & $170(54.4)$ & $9(23.6)$ & $<0.001$ \\
\hline WBC1 & $10.4 \pm 8$ & $10.1 \pm 7.2$ & $12.6 \pm 12.8$ & 0.081 \\
\hline WBC3 & $9.5 \pm 5$ & $9.2 \pm 5$ & $10.8 \pm 4.7$ & 0.112 \\
\hline
\end{tabular}


Table 1 Characteristics of survivors and non-survivors (Continued)

\begin{tabular}{lllll}
\hline & $\begin{array}{l}\text { All patients (\%) } \\
n=350\end{array}$ & $\begin{array}{l}\text { Survivors (\%) } \\
n=312\end{array}$ & $\begin{array}{l}\text { Non-Survivors (\%) } \\
n=38\end{array}$ & $10.6 \pm 4.7$ \\
\hline WBC5 & $10.5 \pm 6.6$ & $10.4 \pm 7$ & 0.932 \\
CURB class & & 256 & 33 & 0.46 \\
$0-2$ & 289 & 56 & 5 \\
$3-5$ & 61 & 5 . & \\
\hline
\end{tabular}

Data are presented as means $\bar{x} \pm \mathrm{SD}$, or $\mathrm{n}(\%), \mathrm{CRP}, \mathrm{C}$-reactive protein; CURB-65, confusion, urea $>7 \mathrm{mmol} / \mathrm{L}$, respiratory rate $\geq 30$ breaths/min, low blood pressure (systolic $<90 \mathrm{~mm} \mathrm{Hg}$ or diastolic $\leq 60 \mathrm{~mm} \mathrm{Hg}$ ) and age $\geq 65$ years

$P C T$ procalcitonin, COPD Chronic Obstructive Pulmonary Disease, SD standard deviation, WBC white blood cell, CRP3C 5c: CRP clearance on day3, day5 PCT3c, 5c PCT clearance on day 3 , day 5

levels on diagnosis is well established [5, 7, 13, 14], The mean values of certain cytokines are statistically different from patients with treatment failure vs patients without treatment failure, the wide range of values for particular cytokines make it difficult to use the value of a single patient to predict clinical outcomes. A dynamic approach of assessing biomarkers may provide additional survival information. Markers of the inflammatory response and their kinetics have been studied in the prediction of outcomes in sepsis [15] and VAP [16, 17]. As reported by Huang MY, et al., PCT clearance (PCTc) has been introduced in a previous studies as a tool for monitoring the changes of PCT levels during severe sepsis $[18,19]$. Similar to PCTc in the previous study, in our study we introduced CRP clearance (CRPC) to monitor the changes of CRP levels during the treatment of hospitalized CAP. Since PCTc and CRPc measures the relative changes in PCT and CRP to the baseline levels, they are postulated to be a better predictor of prognosis. However, both PCTc and CRPc are not common in clinical practice.
Therefore, the hypothesis of this study is whether CRP and PCT levels and their clearance could serve as prognostic biomarkers for hospitalized CAP patients. The aim of the present study was to evaluate the usefulness of CRP and PCT levels and their clearance as prognostic biomarkers for hospitalized CAP patients.

\section{Methods \\ Study design and patient population}

This was a single-center, prospective observational study. Hospitalized pneumonia patients with a radiological confirmation were recruited. The informed consents were obtained from all subjects or their guardians. The study was approved by ethic committee of Zhengzhou University and met the declaration of Helsinki. Diagnosis of CAP required the presence of at least one respiratory symptom in addition to one auscultatory finding or signs of infection $\left(\mathrm{WBC}>10 \times 10^{9} / \mathrm{L}\right.$ or $<4 \times 10^{9} / \mathrm{L}$ cells, shivers, core body temperature $>38.0{ }^{\circ} \mathrm{C}$ ) and a new infiltrate on chest radiograph. The respiratory symptoms included cough, expectoration, dyspnea, tachypnea, or

Table 2 Univariate and multivariate analysis of biomarkers for 30-day mortality

\begin{tabular}{|c|c|c|c|c|c|c|}
\hline & \multicolumn{3}{|l|}{ Univariate analysis } & \multicolumn{3}{|l|}{ Multivariate analysis } \\
\hline & Odds ratio $(95 \% \mathrm{Cl})$ & Estimate & Univariate $P$-value & Odds ratio $(95 \% \mathrm{Cl})$ & Estimate & Multivariate $P$-value \\
\hline CRP1 (mg/L) & $0.998(0.994-1.003)$ & -0.001 & 0.53 & & & \\
\hline CRP3 (mg/L) & $1.006(1.003-1.01)$ & 0.006 & $<0.001$ & $1.013(1-1.025)$ & 0.012 & 0.002 \\
\hline CRP3C & 0.999(0.999-1) & 0 & 0.845 & & & \\
\hline CRP3C $<0$ & $1.02(0.991-1.049)$ & 0.019 & 0.174 & & & \\
\hline CRP5(mg/L) & $1.008(1.004-1.01)$ & 0.008 & $<0.001$ & $1.011(1-1.021)$ & 0.011 & 0.028 \\
\hline CRP5C & $1(0.999-1)$ & 0 & 0.999 & & & \\
\hline PCT1 (ng/mL) & $1.001(0.955-1.05)$ & 0.001 & 0.96 & & & \\
\hline PCT3 (ng/mL) & $1.036(0.998-1.07)$ & 0.035 & 0.06 & & & \\
\hline PCT3C & 0.999(0.999-1) & 0 & 0.966 & & & \\
\hline PCT5 (ng/mL) & $1.21(1.08-1.357)$ & 0.191 & $<0.001$ & $1.277(1.004-1.624)$ & 0.244 & 0.046 \\
\hline PCT5C & $1(0.999-1)$ & 0 & 0.052 & & & \\
\hline WBC1 & 1.025(0.993-1.059) & 0.025 & 0.117 & & & \\
\hline WBC3 & $1.061(0.985-1.143)$ & 0.059 & 0.118 & & & \\
\hline WBC5 & $1.004(0.906-1.113)$ & 0.004 & 0.931 & & & \\
\hline
\end{tabular}


Table 3 Univariate and multivariate analyses of biomarkers for initial treatment failure

\begin{tabular}{|c|c|c|c|c|c|c|}
\hline & \multicolumn{2}{|c|}{ Initial treatment failure } & \multirow{2}{*}{$\begin{array}{l}\text { Univariate Odds } \\
\text { ratio }(95 \% \mathrm{Cl})\end{array}$} & \multirow{2}{*}{$\begin{array}{l}\text { Univariate } \\
P \text {-value }\end{array}$} & \multirow{2}{*}{$\begin{array}{l}\text { Multivariate Odds } \\
\text { ratio(95\% Cl) }\end{array}$} & \multirow{2}{*}{$\begin{array}{l}\text { Multivariate } \\
P \text {-value }\end{array}$} \\
\hline & Yes & $\mathrm{No}$ & & & & \\
\hline CRP1 (mg/L) & $71 \pm 88.7$ & $64 \pm 83.9$ & $0.999(0.996-1.003)$ & 0.55 & $1.008(1.001-1.013)$ & 0.009 \\
\hline CRP3 (mg/L) & $89.2 \pm 107.6$ & $48.9 \pm 66.8$ & $0.995(0.991-0.998)$ & 0.001 & $0.992(0.985-0.999)$ & 0.035 \\
\hline CRP3C & $801.8 \pm 3644.9$ & $501 \pm 5328.5$ & 1 & 0.673 & $1(0.999-1)$ & 0.33 \\
\hline CRP5(mg/L) & $79.7 \pm 96.3$ & $37.2 \pm 58.3$ & 0.993(0.989-0.997) & $<0.001$ & $0.996(0.989-1.001)$ & 0.15 \\
\hline CRP5C & $682.9 \pm 2888.4$ & $371.7 \pm 3614.2$ & 1 & 0.534 & $1(0.999-1)$ & 0.299 \\
\hline PCT1 (ng/mL) & $4.6 \pm 13.6$ & $1.2 \pm 4.2$ & $0.936(0.892-0.983)$ & 0.009 & $0.89(0.82-0.965)$ & 0.005 \\
\hline PCT3 (ng/mL) & $2.8 \pm 11.2$ & $1.4 \pm 4.5$ & $0.975(0.941-1.01)$ & 0.163 & $1.134(1.017-1.263)$ & 0.022 \\
\hline РCT3C & $469.1 \pm 1972.7$ & $865.2 \pm 2784.4$ & 1 & 0.293 & $1(0.999-1)$ & 0.403 \\
\hline PCT5 (ng/mL) & $2.8 \pm 7.3$ & $0.8 \pm 2.1$ & $0.868(0.892-0.983)$ & 0.005 & $0.851(0.751-0.963)$ & 0.01 \\
\hline PCT5C & $1013.8 \pm 2761.2$ & $622.1 \pm 2388.7$ & 1 & 0.268 & $1(0.999-1)$ & 0.658 \\
\hline
\end{tabular}

a Variable(s) entered on step 1: CRP1, CRP3, CRP3c, CRP5, CRP5c, PCT1, PCT3, PCT3c, PCT5, PCT5c, and CURB65

pleuritic chest pain [20]. Radiological findings were verified with results of the real-time PCR tests on blood samples and nasopharyngeal swabs. The Clinical severity of the hospitalized CAP was evaluated by the CURB-65 score, which including confusion, urea, respiratory, and blood pressure plus age $>65$ years.

\section{Measurement of biomarkers}

Followed our study design, WBC counts were measured as a part of routine tests using Beckman-coulter LH750 hematology analyzer. Serum CRP and PCT levels were measured on hospital days 1,3 , and 5 in patients. The blood was drawn in vacuum tube filled with separation gel and centrifuged at $3500 \mathrm{rpm}$ for $5 \mathrm{~min}$, and then CRP and PCT were analyzed by Roche cobas 8000 automatic biochemistry analyzer within $30 \mathrm{~min}$. Concentrations of CRP were determined by an immunoturbidimetric assay. The diagnostic cut-off value of CRP was set by manufacturer at $5 \mathrm{mg} / \mathrm{L}$. PCT $(\mathrm{ng} / \mathrm{mL})$ levels were measured by electro chemiluminescence immunoassay with a lower limit of detection of $0.02 \mathrm{ng} / \mathrm{ml}$. CRP and PCT levels measured on day 1, day 3 and day 5 were defined as CRP1 and PCT1, CRP3 and PCT3, CRP5 and PCT5, respectively. PCTc was calculated based on the previously reported formula [19], (PCTday3/day5-PCTday1) $/ \mathrm{PCT}$ day $1 \times 100 \%=\mathrm{PCT} 3 \mathrm{C}$ /day5c (\%). The calculation of CRPc was referred to the PCTc formula. CRPc on day 3 and day5 were abbreviated as CRP3C and CRP5c.

\section{The detection of CAP pathogen}

Viral RNA or DNA was extracted from the respiratory secretions within $24 \mathrm{~h}$, and was then tested using respiratory virus panel (Shanghai ZJ Bio-Tech Co., Ltd) fast assay to detect influenza A/B virus (lot: RR-0226-02), respiratory syncytial virus (RSV)-A (RR-0160-01) and -B (lot:RR-0160-02), parainfluenzavirus-1, $-2,-3$ and -4 (lot: RR-0156-01,02,03,04), adenovirus (lot:RD-0195-02), human metapneumovirus (hMPV) (lot: RR-0162-02) in accordance with the manufacturer's instructions.

The autolysin-A (LytA) and wzg (cpsA) genes of $S$. pneumoniae were tested using real-time PCR from blood and swab samples for pneumococcal cases according to the manufacture instructions. $M$. pneumoniae was looked for in blood and nasopharyngeal swabs with nested PCR, as described previously [21]. Routine

Table 4 Correlation of biomarkers characteristics at different time

\begin{tabular}{|c|c|c|c|c|c|}
\hline & PCT1(ng/ml) & РСТ3(ng/ml) & PCT5(ng/ml) & РСТ3С & PCT5C \\
\hline CRP1 (mg/L) & $\begin{array}{l}R^{2}=0.35 \\
P=0.0001^{*}\end{array}$ & & & & \\
\hline CRP3 (mg/L) & & $\begin{array}{l}R^{2}=0.19 \\
P=0.0001^{*}\end{array}$ & & & \\
\hline CRP3C & & & & $\begin{array}{l}R^{2}=0.09 \\
P=0.11\end{array}$ & \\
\hline CRP5(mg/L) & & & $\begin{array}{l}R^{2}=0.21 \\
P=0.0001^{*}\end{array}$ & & \\
\hline CRP5C & & & & & $\begin{array}{l}R^{2}=0.17 \\
P=0.002^{*}\end{array}$ \\
\hline
\end{tabular}

Correlation is significant at the 0.01 level (2-tailed)

"Pearson Correlation was used to test the correlation between biomarkers 
microbiological examinations were also performed at the Microbiology laboratory and included blood culture, sputum culture, and antigenuria.

\section{Statistical analysis and data management}

Data were analyzed using SPSS v.17.0 software (SPSS Inc., Chicago, IL, USA) for Windows. Frequency comparison was done using the $\mathrm{X}^{2}$-test. The two-group comparison for continuous data was done with the Mann-Whitney U-test. We used univariate and multivariate logistic regression analysis to study the association between biomarker levels and outcome adjusting the models for the CAP severity score CURB-65 and age. ROC curves were used to evaluate the sensitivity and specificity of PCT and CRP vs pneumonia prognosis. The areas under the curve (AUC) were reported with its 95\% confidence interval (CI). All $p$-values were two-tailed and were considered significant for $p<0.05$.

\section{Outcomes}

The primary endpoint was 30-day mortality and the secondary endpoint was initial treatment failure. Both endpoints were assessed by seven medical students, blinded to the goal and design of the study, by conducting standardized follow-up interviews by telephone at 30 days after baseline. Initial treatment failure was defined as occurring in patients whose antimicrobial agents were changed by the attending physicians because they were ineffective referring to the CAP guideline in China [22]. Serial changes in PCT, CRP, and WBC were analyzed for their potential to estimate the clinical prognosis/outcome.

\section{Results}

Demographics and clinical presentations

Baseline characteristics of survivors and non-survivors were presented in Table 1 . This study included a total of 350 patients with a median age of 58.53 years $(58.3 \%$

Table 5 Prognostic performance of Biomarkers and CURB-65 in predicting pneumonia prognosis

\begin{tabular}{|c|c|c|c|c|}
\hline Variable(s) & AUC & SE & $P$ value & $95 \% \mathrm{Cl}$ \\
\hline$\overline{\text { CRP1 (mg/L) }}$ & 0.45 & 0.05 & 0.37 & $0.36-0.55$ \\
\hline CRP3 (mg/L) & 0.69 & 0.05 & $<0.001$ & $0.6-0.8$ \\
\hline CRP3C & 0.77 & 0.04 & $<0.001$ & $0.7-0.85$ \\
\hline CRP5(mg/L) & 0.76 & 0.05 & $<0.001$ & $0.67-0.85$ \\
\hline CRP5C & 0.81 & 0.03 & $<0.001$ & $0.75-0.87$ \\
\hline PCT1 (ng/mL) & 0.57 & 0.05 & 0.11 & $0.49-0.67$ \\
\hline РCT3 (ng/mL) & 0.61 & 0.05 & 0.02 & $0.52-0.71$ \\
\hline РСТ3С & 0.57 & 0.04 & 0.13 & $0.49-0.66$ \\
\hline PCT5 (ng/mL) & 0.73 & 0.04 & $<0.001$ & $0.65-0.82$ \\
\hline PCT5C & 0.65 & 0.05 & $<0.001$ & $0.57-0.75$ \\
\hline$C R P 1 * P C T 1$ & 0.55 & 0.05 & 0.36 & $0.45-0.65$ \\
\hline $\mathrm{CRP}^{*}{ }^{*} \mathrm{CRP} 3 \mathrm{C}$ & 0.7 & 0.05 & $<0.001$ & $0.6-0.8$ \\
\hline $\mathrm{CRP}^{*} \mathrm{CRP} 5 \mathrm{C}$ & 0.77 & 0.05 & $<0.001$ & $0.68-0.86$ \\
\hline РСТ3*РСТЗС & 0.65 & 0.04 & $<0.001$ & $0.56-0.74$ \\
\hline PCT5*PCT5C & 0.74 & 0.04 & $<0.001$ & $0.66-0.83$ \\
\hline CRP3*PCT3 & 0.7 & 0.05 & $<0.001$ & $0.6-0.81$ \\
\hline CRP3 $C^{*} P C T 3 C$ & 0.76 & 0.04 & $<0.001$ & $0.68-0.84$ \\
\hline CRP5*PCT5 & 0.79 & 0.04 & $<0.001$ & $0.71-0.87$ \\
\hline CRP5C*PCT5C & 0.67 & 0.04 & $<0.001$ & $0.58-0.76$ \\
\hline $\mathrm{CRP}^{*}{ }^{*} \mathrm{CRP} 5 \mathrm{C}^{*} \mathrm{PCT} 5^{*} \mathrm{PCT} 5 \mathrm{C}$ & 0.79 & 0.04 & $<0.001$ & $0.71-0.87$ \\
\hline $\mathrm{CRP}^{*}{ }^{*} \mathrm{CRP} 3 \mathrm{C}^{*} \mathrm{CRP}^{*} \mathrm{CRP} 5 \mathrm{C}$ & 0.85 & 0.04 & $<0.001$ & $0.77-0.92$ \\
\hline PCT3*PCT3 C $^{*}$ CT5*PCT5C & 0.81 & 0.04 & $<0.001$ & $0.73-0.9$ \\
\hline $\mathrm{CRP}^{*}{ }^{*} \mathrm{CRP} 3 \mathrm{C}^{*} \mathrm{CRP}^{*}{ }^{*} \mathrm{CRP} 5 \mathrm{C}^{*}$ PCT3*PCT3 $\mathrm{C}^{*} \mathrm{PCT} 5^{*} \mathrm{PCT} 5 \mathrm{C}$ & 0.81 & 0.04 & $<0.001$ & $0.73-0.88$ \\
\hline CURB-65 & 0.53 & 0.05 & 0.53 & $0.44-0.63$ \\
\hline $\mathrm{CRP}^{*}{ }^{*} \mathrm{CRP} 3 \mathrm{C}^{*} \mathrm{CRP}^{*}{ }^{*} \mathrm{CRP} 5 \mathrm{C}^{*} \mathrm{CURB}-65$ & 0.77 & 0.04 & $<0.001$ & $0.69-0.85$ \\
\hline PCT3*PCT3 C $^{*}$ CT5 5*PCT5 c $^{*}$ CURB -65 & 0.72 & 0.05 & $<0.001$ & $0.64-0.81$ \\
\hline
\end{tabular}

ander the nonparametric assumption

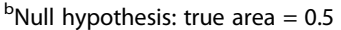

${ }^{\mathrm{c}} \mathrm{ROC}$ receiver operating characteristic, $\mathrm{AUC}$ area under the curve, SE standard error, $\mathrm{Cl}$ confidence interval 
males). The 30-day mortality was found in $10.86 \%$ (38/ 350) of all patients. Patients had a high burden of comorbidities including chronic heart disease $(n=100)$, chronic liver disease $(n=22)$, chronic renal disease $(n=47)$, malignant disease $(n=26)$, Chronic Obstructive Pulmonary Disease (COPD, $n=22)$ and diabetes $(n=30)$. Cough $(n=$ $268,76.6 \%)$ and dyspnea $(n=249,71.1 \%)$ were the most frequent symptoms. No significant differences of comorbidities and symptoms were found between survivors and non-survivors. CAP was ascribed to bacteria in 176 (50.29\%) patients and to one or more viruses in 115 (32.86\%) patients (Additional file 1: Table S1). Serial serum CRP3, CRP5, PCT3, PCT5 and PCT5c levels were statistically lower in CAP survivors than non-survivors (Table 1 ). CRP3c $<0$, CRP5 $c<0$ and PCT5c $<0$ were observed with a statistically lower frequency in patients with 30-day mortality (Table 1).

\section{Statistic analysis for clinical factors and CAP}

WBCs, CRP, and PCT levels on hospital days 1, 3, and 5 and their clearance were compared in all groups. The average mean value of these biomarkers comparison is reported in Tables 2, 3 and Additional file 2: Table S2. ANOVA analysis showed that the CAP patients with bacteria pathogens had significantly higher values of CRP and PCT $(P<0.05)$ than those with other causative pathogens (Additional file 2: Table S2).

We used univariate and multivariate logistic regression models to investigate associations between serum biomarker levels and outcome (Table 2). In univariate analysis, no significant association of CRP1 [OR (95\% CI): 0.998(0.9941.003)] and PCT1 levels [OR (95\% CI): 1.001(0.955-1.05)] or WBC counts with 30-day mortality was found. Significant predictive ability was found for 30-day mortality with CRP3 [OR (95\% CI): 1.006(1.003-1.01)], CRP5 [OR (95\% CI): 1.008(1.004-1.01)] and PCT5 [OR (95\% CI): 1.21(1.081.357)] levels respectively. The significance did not disappear after adjust for age, sex and CURB-65 in multivariate logistic regression model.

This study did not show that patients with initial treatment failure had significant higher CRP1 levels than others ( 71 vs $64, P=0.55)$. On the other hand, patients with initial treatment failure had significantly higher levels of CRP3, CRP5, PCT1, PCT3 and PCT5 than others (Table 3), which indicated that serial measurements of these serum biomarker levels were also useful for predicting whether initial CAP treatment would be successful.

\section{Correlation between PCT and CRP and their clearance}

Assessment of correlation between biomarkers was performed by Spearman's rank correlation analysis. Table 4 showed correlations of CRP, PCT and their clearance in the overall population. At baseline, day 3 and day 5, we found significant correlations between PCT and CRP, no correlations were found for PCT3C and CRP3c $\left(\mathrm{R}^{2}=0.09\right.$, $P=0.11$ ). However, the maximum correlation coefficient was 0.35 , which is smaller than 0.8 , indicating the low level of multicollinearity among each biomarker.

\section{Prognostic accuracy of serial values of PCT and CRP}

Table 5 showed the ROC curve of each biomarker and each biomarker combined. For the single biomarker, the peak areas under the ROC curve of CRP5C and PCT5 to predict 30 -day mortality was 0.81 (95\%CI: $0.75-0.87$; $P$ $<0.001$ ) and 0.73 (95\%CI: $0.65-0.82 ; P<0.001)$, respectively (Table 5, Fig. 1a, b). The capacity of serial serum biomarkers combined to predict 30-day mortality was higher than only one biomarker or a combination of two of the biomarkers. The AUC for 30-day mortality for serial CRP levels combined with CRP clearances was 0.85 (95\% CI 0.77-0.92), as compared to an AUC of 0.81 (95\% CI 0.73-0.9) for serial PCT levels combined with PCT clearances. Furthermore, their AUC-ROC did not increase if they were used in combination with CURB65 (Table 5, Fig. 2c, d).
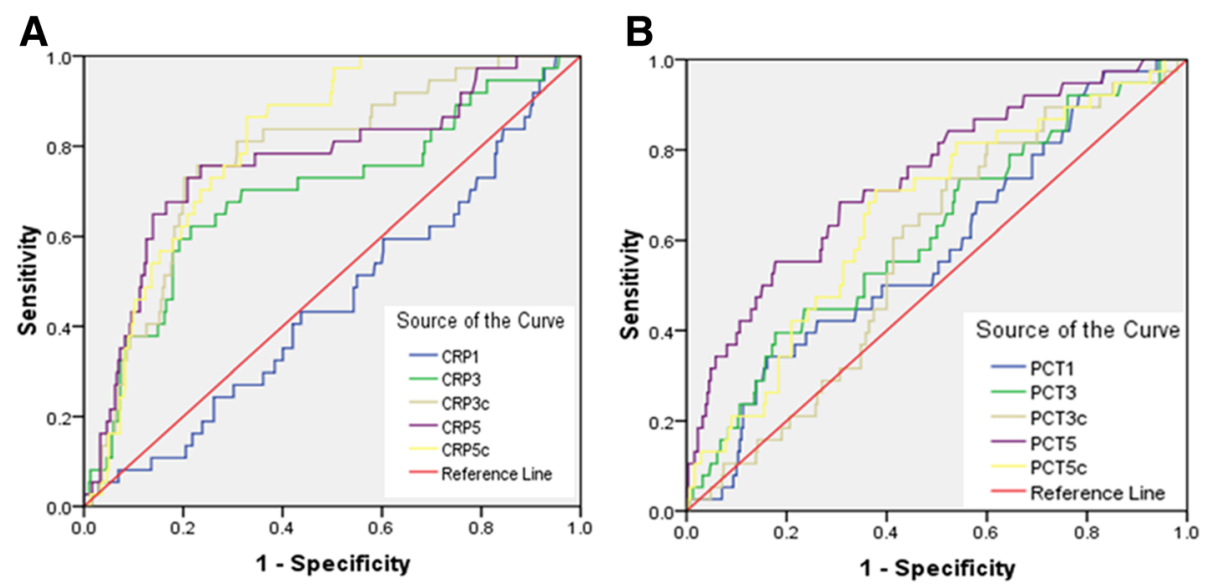

Fig. 1 ROC curve of CRP, PCT levels and their clearance vs pneumonia prognosis 


\section{Discussions}

In accordance with the current literature, the clinical characteristics of the patients included in this study frequently had a comorbidity of respiratory disorders, diabetes mellitus, congestive heart failure and cancer [23]. So far, most studies focused on the diagnostic performance of serum biomarkers, especially CRP and PCT on the pneumonia diagnosis $[1,5,7,11,24,25]$. Only very few research studied the predictive value of serum biomarkers in the pneumonia outcomes $[6,14,17,26-28]$. A dynamic approach to biomarkers could capture the progression of disease and might be more effective in evaluating pneumonia prognosis.

In this context, we observed serum CRP and PCT levels measured at different time points after admission. The main findings of this study are threefold. First, circulating CRP and PCT levels were significant different in the pneumonia patients infected with different pathogens. However, there was no significance of the serum CRP1 and PCT1 levels between survivors and non-survivors. This indicated that the initial CRP and PCT levels could not provide useful information to assist with mortality prediction in hospitalized CAP patients, which was consistent with the results from previous studies. Previous studies had showed that simply measuring the initial CRP and PCT levels did not improve clinical score for mortality but that following the kinetics of PCT did so [6, 29]. However, Akihiro ITO's study found that the initial CRP and PCT levels were significant different between survivors and non-survivors [30]. Furthermore, they found that PCT levels on day $3 /$ day $1 \geq 1$, CRP levels on day $1 \geq 100 \mathrm{mg} / \mathrm{L}$ and CURB- $65 \geq 3$ were prognostic variables in CAP. The different basic characteristics of research groups in these studies were the main reasons for the different results. The average age in our study was younger than Akihiro ITO's study (58.53 vs. 73.2), while composition ratio of CURB-65 class was similar (Class $0-2: 82.6$ vs. 75.9 , Class 3-5: 17.4 vs. 24.1). Similar proportion of CURB-65 in the population aged below and above 65 years old, indicating the more complicate comorbidities or more severe CAP disease in our study which resulting the similar initial CRP and PCT levels between survivors and non-survivors.

Second, consistent with the previous report [6], CRP levels were independent prognostic predictors of CAP clinical outcomes. PCT has been used as a biomarker for initiating or terminating antibiotic therapy in various clinical settings in the previous studies [31, 32]. In this work, we confirmed the predictive role of CRP and PCT in CAP prognosis. Serial serum CRP3, CRP5, PCT3, PCT5 and PCT5c levels were statistically lower in CAP survivors than non-survivors. CRP3c $<0$, CRP5c $<0$ and PCT5c $<0$ were observed with a statistically lower frequency in

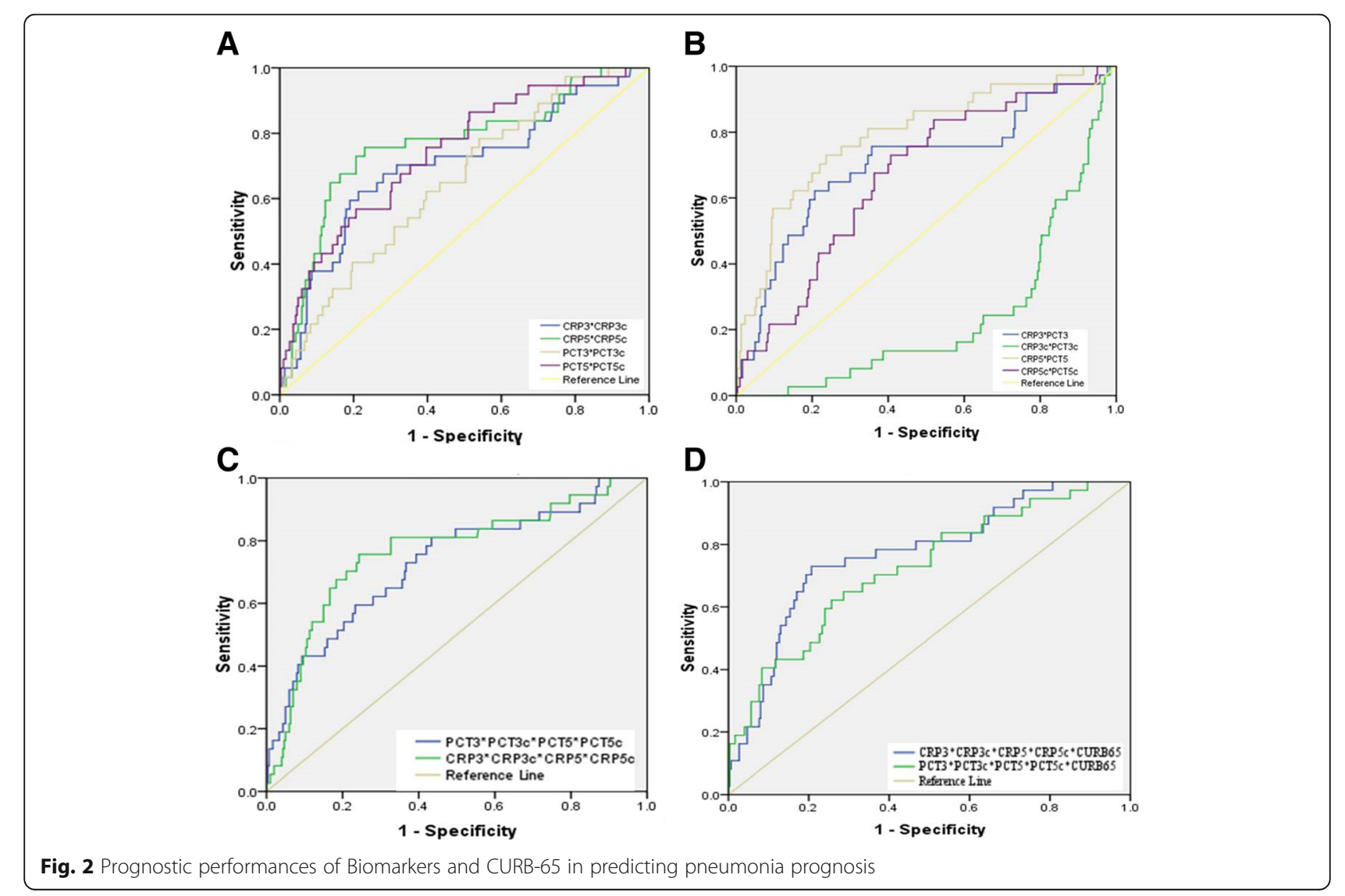


patients with 30-day mortality and initial treatment failure. Significant predictive ability was found for 30-day mortality with CRP3, CRP5 and PCT5 levels.

Third, there was low level of multicollinearity among each biomarker. The capacity of serial serum biomarkers combined to predict 30-day mortality was higher than only one biomarker or a combination of two of the biomarkers. Though the CRP and PCT clearances were not directly associated with the CAP prognosis, when combined with the serum biomarker levels, the increased AUC-ROC indicated the greater prognosis capacity. This was consistent with previous report [33], CRP kinetics can be used to identify ventilator-associated pneumonia patients with poor outcome. This also highlighted the necessary to measure the values of serum biomarkers serially. However, the combination with CURB65 did not increase the predictive AUC-ROC of serum biomarker.

There were some limitations in our study. Firstly, the missing data for laboratory biomarkers in some patients, potential classification bias in the etiologic diagnosis. However, our evaluation has been done in a large study population even excluding missing data. Secondly, since the average age of the patients in our study was near 60 years old, whether these results are generalizable to CAP patients in children or aged greater than 80 years old needs further evaluation. Finally, the objects studied usually combined with other diseases, which might affect the serum CRP and PCT levels. But the complicated diseases were the true status for most hospitalized CAP patients. Thus, further studies with a prospective design are needed to explore the influence of other comorbidity on the biomarkers level and hospitalized CAP prognosis.

\section{Conclusions}

This is a large and comprehensive study focused on the predictive value of serum dynamic CRP, PCT levels and their clearance in hospitalized CAP outcomes. The low correlations between the two biomarkers and the only moderate prognostic accuracy calls for a head-to-head trial comparing the ability of both markers to monitor the therapeutic effect and to answer the question which marker is superior in the prognosis prediction

\section{Key messages}

The dynamic serum CRP and PCT levels have moderate predictive value on the prognosis of hospitalized CAP.

\section{Additional files}

Additional file 1: Table S1. Viral and bacterial data for patients classified as "definite CAP. (DOCX $13 \mathrm{~kb}$ )

Additional file 2: Table S2. Comparisons of biomarkers characteristics within pneumonia patients infected by different pathogens. (DOCX $15 \mathrm{~kb}$ )

\section{Abbreviations}

AUC: Areas under the curve; CAP: Community-acquired pneumonia; CCl: Charlson Comorbidity Index; Cl: Confidence interval; CRP: C-reactive protein; CRPc: CRP clearance; PCT: Procalcitonin; PCTc: PCT clearance; ROC: Receiver operating characteristic; VAP: Ventilator- associated pneumonia; WBC: White blood cell count

\section{Funding}

This research received no specific grant from any funding agency in the public, commercial, or not for-profit sectors.

\section{Availability of data and materials}

The data that support the findings of this study are available from the The first affiliated Hospital of Zhengzhou university but restrictions apply to the availability of these data, which were used under license for the current study, and so are not publicly available. Data are however available from the authors upon reasonable request and with permission of The first affiliated Hospital of Zhengzhou university.

\section{Authors' contributions}

SG and XM contributed to designing the study, interpreting data, drafting the manuscript. ML contributed to designing the study, acquisition of and interpreting data and approving the final version of the manuscript. All authors read and approved the final manuscript.

\section{Ethics approval and consent to participate}

The study protocol was approved by local ethics committee. All phases of the study were carried out in conformity with the principles expressed in the Declaration of Helsinki. Written informed consent was obtained according to Chinese law.

\section{Consent for publication}

The study was approved by ethic committee of Zhengzhou University. The informed consents were obtained from all subjects or their guardians.

\section{Competing interests}

The authors declare that there are no competing interests.

\section{Publisher's Note}

Springer Nature remains neutral with regard to jurisdictional claims in published maps and institutional affiliations.

\section{Author details}

${ }^{1}$ Department of Clinical Laboratory, The First Affiliated Hospital of Zhengzhou University, East Jianshe Road \#1, Zhengzhou, Henan 450002, People's Republic of China. ${ }^{2}$ Key Clinical Laboratory of Henan province, Zhengzhou, Henan, People's Republic of China. ${ }^{3}$ Department of Clinical Laboratory, Henan Provincial People's Hospital, Henan Province, Zhengzhou 450003, People's Republic of China.

Received: 1 June 2018 Accepted: 3 September 2018

Published online: 01 October 2018

References

1. Nouvenne A, Ticinesi A, Folesani G, Cerundolo N, Prati B, Morelli I, Guida L, Lauretani $F$, Maggio $M$, Aloe $R$, et al. The association of serum procalcitonin and high-sensitivity C-reactive protein with pneumonia in elderly multimorbid patients with respiratory symptoms: retrospective cohort study. BMC Geriatr. 2016;16:16

2. Gonzalez-Castillo J, Martin-Sanchez FJ, Llinares P, Menendez R, Mujal A, Navas E, Barberan J, Spanish Society of Emergency M, Emergency C, Spanish Society of $\mathrm{G}$, et al. Guidelines for the management of community-acquired pneumonia in the elderly patient. Rev Esp Quimioter. 2014;27:69-86.

3. Faverio P, Aliberti S, Bellelli G, Suigo G, Lonni S, Pesci A, Restrepo MI. The management of community-acquired pneumonia in the elderly. Eur J Intern Med. 2014;25:312-9.

4. Cheng CW, Chien MH, Su SC, Yang SF. New markers in pneumonia. Clin Chim Acta. 2013;419:19-25.

5. Agnello L, Bellia C, Di Gangi M, Lo Sasso B, Calvaruso L, Bivona G, Scazzone $C$, Dones $P$, Ciaccio M. Utility of serum procalcitonin and $C$-reactive protein 
in severity assessment of community-acquired pneumonia in children. Clin Biochem. 2016;49:47-50.

6. Zhydkov A, Christ-Crain M, Thomann R, Hoess C, Henzen C, Werner Z, Mueller B, Schuetz P. Pro HSG: Utility of procalcitonin, C-reactive protein and white blood cells alone and in combination for the prediction of clinical outcomes in community-acquired pneumonia. Clin Chem Lab Med. 2015; 53:559-66.

7. Habib SF, Mukhtar AM, Abdelreheem HM, Khorshied MM, El Sayed R, Hafez MH, Gouda HM, Ghaith DM, Hasanin AM, Eladawy AS, et al. Diagnostic values of CD64, C-reactive protein and procalcitonin in ventilator-associated pneumonia in adult trauma patients: a pilot study. Clin Chem Lab Med. 2016;54:889-95

8. Ballou SP, Kushner I. C-reactive protein and the acute phase response. Adv Intern Med. 1992;37:313-36.

9. Cabral L, Afreixo V, Almeida L, Paiva JA. The use of Procalcitonin (PCT) for diagnosis of Sepsis in burn patients: a meta-analysis. PLoS One. 2016;11: e0168475.

10. Yan ST, Sun LC, Jia HB, Gao W, Yang JP, Zhang GQ. Procalcitonin levels in bloodstream infections caused by different sources and species of bacteria. Am J Emerg Med. 2017;35:579-83.

11. Porfyridis I, Georgiadis G, Vogazianos P, Mitis G, Georgiou A. C-reactive protein, procalcitonin, clinical pulmonary infection score, and pneumonia severity scores in nursing home acquired pneumonia. Respir Care. 2014;59: 574-81.

12. Steichen O, Bouvard E, Grateau G, Bailleul S, Capeau J, Lefevre G. Diagnostic value of procalcitonin in acutely hospitalized elderly patients. Eur J Clin Microbiol Infect Dis. 2009;28:1471-6.

13. Meili M, Kutz A, Briel M, Christ-Crain M, Bucher HC, Mueller B, Schuetz P. Infection biomarkers in primary care patients with acute respiratory tract infections-comparison of Procalcitonin and C-reactive protein. BMC Pulm Med. 2016;16:43

14. Khan F, Owens MB, Restrepo M, Povoa P, Martin-Loeches I. Tools for outcome prediction in patients with community acquired pneumonia. Expert Rev Clin Pharmacol. 2017;10:201-11.

15. Yentis SM, Soni N, Sheldon J. C-reactive protein as an indicator of resolution of sepsis in the intensive care unit. Intensive Care Med. 1995:21:602-5.

16. Luyt CE, Guerin V, Combes A, Trouillet JL, Ayed SB, Bernard M, Gibert C, Chastre J. Procalcitonin kinetics as a prognostic marker of ventilatorassociated pneumonia. Am J Respir Crit Care Med. 2005;171:48-53.

17. Abula A, Wang Y, Ma L, Yu X. The application value of the procalcitonin clearance rate on therapeutic effect and prognosis of ventilator associated pneumonia. Zhonghua Wei Zhong Bing Ji Jiu Yi Xue. 2014;26:780-4.

18. Huang MY, Chen CY, Chien JH, Wu KH, Chang YJ, Wu KH, Wu HP. Serum Procalcitonin and Procalcitonin clearance as a prognostic biomarker in patients with severe Sepsis and septic shock. Biomed Res Int. 2016;2016: 1758501.

19. Ruiz-Rodriguez JC, Caballero J, Ruiz-Sanmartin A, Ribas VJ, Perez M, Boveda $J$, Rello J. Usefulness of procalcitonin clearance as a prognostic biomarker in septic shock. A prospective pilot study. Med Int. 2012;36:475-80.

20. Woodhead M, Blasi F, Ewig S, Huchon G, leven M, Ortqvist A, Schaberg T, Torres A, van der Heijden G, Verheij TJ, et al. Guidelines for the management of adult lower respiratory tract infections. Eur Respir J. 2005; 26:1138-80.

21. Principi N, Esposito S, Blasi F, Allegra L. Mowgli study g: role of mycoplasma pneumoniae and chlamydia pneumoniae in children with communityacquired lower respiratory tract infections. Clin Infect Dis. 2001;32:1281-9.

22. Cao B, Huang Y, She DY, Cheng QJ, Fan H, Tian XL, Xu JF, Zhang J, Chen Y, Shen $N$, et al. Diagnosis and treatment of community-acquired pneumonia in adults: 2016 clinical practice guidelines by the Chinese thoracic society, Chinese Medical Association. Clin Respir J. 2018;12:1320-60.

23. Fine MJ, Auble TE, Yealy DM, Hanusa BH, Weissfeld LA, Singer DE, Coley CM, Marrie TJ, Kapoor WN. A prediction rule to identify low-risk patients with community-acquired pneumonia. N Engl J Med. 1997;336:243-50.

24. Le Bel J, Hausfater P, Chenevier-Gobeaux C, Blanc FX, Benjoar M, Ficko C, Ray P, Choquet C, Duval X, Claessens YE. Group Es: diagnostic accuracy of C-reactive protein and procalcitonin in suspected community-acquired pneumonia adults visiting emergency department and having a systematic thoracic CT scan. Crit Care. 2015;19:366.

25. Colak A, Yilmaz C, Toprak B, Aktogu S. Procalcitonin and CRP as biomarkers in discrimination of community-acquired pneumonia and exacerbation of COPD. J Med Biochem. 2017;36:122-6.
26. Ugajin M, Yamaki K, Hirasawa N, Yagi T. Predictive values of semiquantitative procalcitonin test and common biomarkers for the clinical outcomes of community-acquired pneumonia. Respir Care. 2014;59:564-73.

27. Fernandez JF, Sibila O, Restrepo MI. Predicting ICU admission in community-acquired pneumonia: clinical scores and biomarkers. Expert Rev Clin Pharmacol. 2012:5:445-58.

28. Kim MW, Lim JY, Oh SH. Mortality prediction using serum biomarkers and various clinical risk scales in community-acquired pneumonia. Scand J Clin Lab Invest. 2017;77:486-92.

29. Schuetz P, Suter-Widmer I, Chaudri A, Christ-Crain M, Zimmerli W, Mueller B. Prognostic value of procalcitonin in community-acquired pneumonia. Eur Respir J. 2011;37:384-92

30. Ito A, Ishida T, Tachibana H, Ito Y, Takaiwa T. Serial procalcitonin levels for predicting prognosis in community-acquired pneumonia. Respirology. 2016; 21:1459-64.

31. Bouadma L, Luyt CE, Tubach F, Cracco C, Alvarez A, Schwebel C, Schortgen $F$, Lasocki S, Veber B, Dehoux M, et al. Use of procalcitonin to reduce patients' exposure to antibiotics in intensive care units (PRORATA trial): a multicentre randomised controlled trial. Lancet. 2010;375:463-74.

32. Mokart $D$, Leone M. Procalcitonin in intensive care units: the PRORATA trial. Lancet. 2010;375:1605. author reply 1606-1607

33. Povoa P, Martin-Loeches I, Ramirez P, Bos LD, Esperatti M, Silvestre J, Gili G, Goma G, Berlanga E, Espasa M, et al. Biomarkers kinetics in the assessment of ventilator-associated pneumonia response to antibiotics - results from the BioVAP study. J Crit Care. 2017;41:91-7.
Ready to submit your research? Choose BMC and benefit from:

- fast, convenient online submission

- thorough peer review by experienced researchers in your field

- rapid publication on acceptance

- support for research data, including large and complex data types

- gold Open Access which fosters wider collaboration and increased citations

- maximum visibility for your research: over $100 \mathrm{M}$ website views per year

At $\mathrm{BMC}$, research is always in progress.

Learn more biomedcentral.com/submissions 